Revista Iberoamericana, Vol. LXVII, Núm. 197, Octubre-Diciembre 2001, 661-670

\title{
VIGENCIA Y CADUCIDAD DEL LIBRO: REFLEXIONES DE UNA LECTORA ERRÁTICA
}

POR

Celeste Olalquiaga

¿Es un libro más real por aparecer sobre una superficie fija de tinta y papel que en aquélla más fluida de una pantalla fluorescente? ¿A qué grado de legitimidad cultural pueden aspirar los textos que aparecen en la red electrónica? ¿Qué ocurrirá con el objeto libro y con su depositario privilegiado, las bibliotecas?

Tales interrogantes giran en torno al supuesto de que la experiencia conocida o heredada es portadora de un mayor grado de autenticidad que aquella que viene a reemplazarla, fundamento de buena parte de los argumentos en contra de cualquier tipo de modernización. Enfrentado por la renovación cultural de principios del siglo xx con el concepto de "originalidad" — principio fundador y por tanto ajeno a jerarquías de antigüedad - tanto el dilema de la prioridad como su solución modernista han perdido desde entonces vigencia. Hoy en día, nos encontramos frente a una realidad que escapa a las dicotomías clásico/moderno, tradicional/innovador, original/copia; pues se presenta nada menos que como un nuevo tipo de realidad: una que no es factual sino virtual —es decir, potencial - en tanto ocupa o emula el espacio a la vez intangible y ubicuo de la red electrónica, metáfora de un inconsciente colectivo aún no enunciado como tal.

\section{EL INCONSCIENTE ELECTRÓNICO}

La red electrónica y su realidad virtual manifiestan una volatilidad sin precedentes, producto de los elementos más obvios de este sistema: velocidad y globalidad. Éstos, a su vez, son consecuencia de la relativa immaterialidad de este sistema, el cual, dependiente aún de un soporte físico constituido por computadoras, cables de electricidad y líneas telefónicas, deviene progresivamente más transparente e intangible al reducirse en volumen y liberarse del contacto humano directo. Esto ocurre a través de mecanismos cada vez más condensados y ligeros de proyección y comunicación como la fibra óptica y el láser, así como de técnicas de reconocimiento basadas en emanaciones sonoras o térmicas como la voz o el calor del cuerpo, respectivamente.

Así, la realidad virtual reconstituye dos de los parámetros fundamentales de la sensibilidad humana: espacio y tiempo. El espacio implica no sólo el contexto exterior en el cual nos movemos, sino aquél hasta ahora interior e individual de nuestros cuerpos; ambos están perdiendo su fisonomía propia y confundiéndose tanto entre sí como con la 
red electrónica que los (re)presenta. El tiempo ha pasado de ser concebido como una continuidad azarosa, fragmentaria y múltiple, —-pero básicamente cronológica y de alguna manera cuantificable - a una instantaneidad permanente, flexible e inconmensurable, desinteresada de todo lo que no la potencialice: el pasado, percibido básicamente como un cofre iconográfico, y el futuro irrelevante pues no existe todavía.

Es el momento de la desaparición de los límites entre interior y exterior; antes, ahora y después: en la transacción con lo tecnológico, el cuerpo se convierte en un emisor/ receptor de señales y registros; es decir, participa de un sistema cibernético en el cual las categorías de humanidad (individualidad, emoción, memoria) son desplazadas por las de una materialidad cada vez más evanescente, cuyo éxtasis sensorial y perceptual desplaza la continuidad afectiva.

En este contexto, la cuestión del libro y de la lectura, objeto y práctica pretecnológicos, cobran particular interés en tanto representantes de un cierto modo de vida. Después de todo, cuando nos preguntamos por el destino del libro, lo hacemos más bien por la totalidad de su experiencia: el acto de tomar un objeto entre las manos e involucrarnos táctil, visual, cognoscitiva, emocional e imaginariamente con el mismo, con todo lo que cada uno de estos registros implica. Por lo tanto, no es tan solo el acto de leer lo que está en jaque, sino la experiencia física del objeto libro, así como también la configuración y circulación de los textos.

La pregunta, entonces, no es si el modo de vida en que crecimos es más auténtico que aquel en que nos está tocando, querámoslo o no, evolucionar. En estas circunstancias, el dilema de la autenticidad es absolutamente irrelevante, no sólo porque no tiene cabida en un discurso que se renueva constantemente (eliminando cualquier referencialidad estable a la cual podría anclarse la noción de autenticidad, así sea la de una tradición interrumpida, como ocurrió en los siglos XIX y xx) sino porque, al utilizar la autenticidad como elemento de juicio, nos impedimos comprehender un proceso que resultará indispensable para nuestra propia sobrevivencia social.

La pregunta es más bien cómo integrar de manera significativa y relativamente armoniosa dos formas dispares de vida: una, pre-tecnológica, cuya experiencia física es personal, palpable y deja trazas que a su vez son elaboradas culturalmente; la otra, tecnológica, con una experiencia física que se remite cada vez más a lo sensorial, que es percibida como algo colectivo (en esto, los “raves” de música tecnológica, con drogas que exacerban la sensación y la sociabilidad, son sintomáticos) y, sobre todo, no deja o no se ocupa de sus trazos; es decir, es vivida en y por el momento, siendo el presente la última instancia de cualquier transcendencia posible.

En este sentido, podemos afirmar que la nuestra sí es, después de todo, una era apocalíptica, solo que de acción diferida: en vez de los escenarios catastróficos profetizados para la vuelta del milenio, la cultura tecnológica es una especie de apoteosis del presente que, a diferencia de la desilusión posmodernista de las últimas décadas del siglo pasado, muestra una feliz indiferencia hacia las nociones de desarrollo, progreso y futuro que caracterizaron al ímpetu moderno industrial.

¿Cuál es, entonces, el destino del libro, y de la lectura, en la era electrónica? Una tranformación radical de su modo de producción y consumo, la cual terminará convirtiéndolo en algo completamente diferente e independiente de lo que hemos conocido hasta ahora. 
Esto no quiere decir que todo cambiará de la noche a la mañana, en parte porque hay modos y hábitos de lectura que se pueden acomodar a un texto en pantalla, y otros que no. Cuesta, por ejemplo, concebir una lectura continua, sostenida durante varias horas, frente a una pantalla fluorescente, aun cuando ésta tenga la virtud de prescindir de fuentes de luz externas. No me refiero tan solo a los efectos nocivos de estos aparatos sobre la salud, aspecto que probablemente la tecnología logrará superar, sino a una serie de rituales difíciles de replicar tecnológicamente, pues tienen que ver con una dinámica específica al papel.

Pienso, por ejemplo, en la costumbre de marcar y comentar los textos, imprimiéndoles una marca personal: doblar las puntas de las páginas, subrayar frases, usar códigos de señalización con respecto a la importancia, claridad y concordancia de lo escrito con las ideas del lector, escribir notas al margen, etc. Si bien la tecnología proporciona modos de replicar algunos de estos comportamientos, apenas logra todavía sustituir esa relación tan particular e íntima que se establece entre una persona y un objeto que ha sido manipulado, doblado, hojeado y olfateado; es decir, que de alguna manera se ha impregnado a través del uso y el contacto físico, convirtiéndose a su vez en algo propio y vivido, en una parte tangible de la experiencia individual.

Quizá sea esta tangibilidad amenazada lo que atrae tanto de los manuscritos y pergaminos antigüos, que aparte de su escasez y valor testimonial, ostentan una textura densa y porosa debido tanto al origen orgánico de sus materias (piel y pluma de animales, tinta vegetal) como al trazado manual de palabras e ilustraciones. Los escribanos llegaban a dejar parte de su cuerpo (el sudor y la saliva, por no hablar de los rastros y firmas de sangre) en los textos que copiaban. A esto se añade la marca física del paso del tiempo: el color amarillento, la topografía ondulante ocasionada por el gradual encogimiento de las superficies, lo polvoroso de los primeros libros de papel —un proceso de deterioro que contribuye a su manera con la historia de la producción pre-industrial.

Es en la tangibilidad donde radica, a mi modo de ver, la distinción y escogencia finales de una forma de leer sobre otra, y en este sentido me parece instructivo observar lo que ha ocurrido con los discos y el láser, ya que se trata aquí del retorno de un modo pretecnológico y de su reciclaje, por así llamarlo, en función de un nuevo contexto. Tras haber sido violentamente erradicados por los discos compactos (los cassettes funcionando como instancia intermedia que jamás logró desplazar al vinil, debido tanto a la baja fidelidad como a la secuencialidad no selectiva —impedimento de una selección directa— de las cintas magnéticas, por lo demás fastidiosas y delicadas), los discos de vinil son recuperados apenas años después de su declive para hacer mezclas sonoras de música electrónica.

Esta recuperación ocurre no slo en el plano del contenido, siendo que el aspecto olvidado, perdido o simplemente desconocido de las músicas reproducidas masivamente en vinil proporciona cierto exotismo y placer fetichista, sobre todo a una generación cuyo contexto referencial rara vez excede su propio ciclo de vida. Recuperar al objeto en su totalidad incluye, por supuesto la carátula, pero también un tipo de sonido: para los expertos, el vinil ostenta una textura sonora particular que toda la fidelidad del láser no puede reemplazar o, peor aún, neutraliza, toda vez que esta sonoridad emana del medio mismo en que es producida. Asimismo, el vinil permite una serie de juegos sonoros (sobre la base de invertir la dirección de rotación del disco, apoyar la aguja con mayor o menor 
ligereza para lograr distintos tipos de fricción, manipular al ojo las pistas sonoras) que en definitiva pueden traducirse en una manifestación de la materialidad del disco, eso sí, reproducida, ampliada, mezclada y, sobre todo, interpretada a través de la alta tecnología.

En fin, lo que estoy tratando de subrayar aquí es cómo aun en una instancia donde la sustitución de una técnica por otra parecería tan evidente como en el caso de los discos de vinil, dadas las grandes ventajas (alta fidelidad, ligereza, movilidad) de los discos compactos, la oferta tecnológica no determina de por sí su modo de consumo. En el caso de la recuperación de los discos de vinil, considerados como objetos de colección por la generación “tecno", que se conecta así con la memoria musical de generaciones anteriores, ilustra cuán sorprendentes, diversos e innovadores pueden ser estos usos, aun cuando sus repercusiones culturales no transciendan cierta nostalgia irónica.

La diferencia entre el disco de vinil y el disco compacto reside en la llamada tecnología digital, registro numérico y, por lo tanto, indirecto, discontinuo y neutro, que contrasta abiertamente con la tecnología anterior, la analógica, cuya inscripción se efectúa a través de elementos y no de signos, haciéndola más directa, continua e indicativa. En otras palabras, en vez de una inscripción inmediata sobre la materia, que le ocasionaría una transformación (pensemos, por ejemplo, en la emulsión fotográfica, que altera químicamente el papel), la tecnología digital reproduce a través de un lenguaje codificado; es decir, simbólico y mediato.

En lugar de una imagen análoga, que establece similitud con base en una solución de continuidad espacial entre distintos elementos, lo que aparece sobre una pantalla es un facsímil numérico, cuya semejanza está dada a través de una abstracción simbólica, resultando así una imagen mental y no una presencia material. Si bien la diferencia entre una y otra puede ser sutil a primera vista, no ocurre lo mismo a un nivel perceptual más profundo. Al igual que al ver una foto tenemos una conciencia relativa de estar frente a una representación, por distorsionante o autónoma que ésta pueda ser, al ver una imagen virtual captamos que se trata de la representación de una representación; es decir, de una imagen altamente mediatizada, intangible y apenas referencial: una imagen cuya percepción es cognoscitiva y no sensorial, y que por lo tanto se corresponde perfectamente a su denominación como imagen virtual.

La diferencia entre un libro material y uno virtual es aún más imperceptible, toda vez que se trata aquí de la traducción de un sistema abstracto de signos a otro, este último “camuflado” para dar la apariencia del primero. Así, las letras que vemos en una pantalla fluorescente son aglomeraciones de puntos formuladas a partir de un código binario, y las palabras, conjunciones de letras ejecutadas, igualmente, en un lenguaje automático y exógeno, ajeno al tipo de significatividad que determina al lenguaje humano. Encontramos aquí, pues, tres discontinuidades: la de la impresión de tinta sobre papel, sustituida por pulsiones eléctricas; la del trazo continuo de una letra, cuya unicidad es fracturada para convertirla en la suma de sus partes; y la de la coherencia semántica del idioma, que pasa de ser la manifestación específica de un sistema de signos, a una concatenación circunstancial e infinitamente reprogramable de los mismos.

Aun cuando el resultado final sea indistinguible de una escritura manual o impresa (y la diferencia es irrelevante en cuanto a legitimidad o autoridad conceptual, lo que interesa aquí es la percepción simbólica de los distintos medios), el simulacro tecno- 
lingüístico es desenmascarado cada vez que intentamos transferir un texto de un programa a otro. Dicha transferencia requiere un sistema de traducción que, al fracasar, nos presenta el texto como una jerigonza indescifrable -el llamado lenguaje de computadora, representante de un conjunto de operaciones que determinan la presentación estrictamente estética (es decir, de pura forma) de un texto en su fase electrónica.

Esta distinción, pues, entre una representación material o análoga y otra virtual o numérica, es la que subyace a la llamada autopista informática, toda vez que el traslado a un lenguaje digital (requisito para la transmisión electrónica) libera del peso de la materialidad, permitiendo una circulación más ágil de la información. De más está decir que esta transición de una realidad material a otra virtual implica la distorsión, para bien o para mal, de la primera, que pierde sus atributos de especificidad significativa para ganar aquéllos, genéricos y arbitrarios, del valor de cambio. Pues, ¿qué es en definitiva esta traducción de lo específico, concreto y singular a un sistema universal, fluido y homogeneizante sino la culminación de la abstracción de la realidad comenzada con el dinero y reproducida con el capital?

En este sentido, poco importa el reciente fracaso mercantil y bursátil del Internet: éste soólo indica que los nuevos mecanismos aún no están perfectamente en su lugar. El cambio profundo, la verdadera revolución tecnológica, es una transformación mucho más esencial, pues se está efectuando a nivel ontológico, permitiéndonos desde ya pensar como computadoras, es decir, manejar la realidad a través de un lenguaje binario que la desnuda de toda la complejidad sensorial, afectiva e intelectual con que hemos estado acostumbrados hasta ahora a vislumbrarla. Es la realidad concebida no como experiencia transformadora, sino como vivencia fugaz que se proyecta infinitamente en una tridimensionalidad sin pasado ni futuro. En este sentido, las pantallas pueden ser vistas como ventanas a un nuevo inconsciente colectivo.

\section{2001: OdISEA ESPACIAL Y TEMPORAL}

La transformación radical hacia un modo de ser cada vez más mediatizado por la tecnología electrónica, es decir, por un aparato exterior a nosotros pero con cuyo sistema nos (con)fundimos cibernéticamente, se debe no al aparato mismo, sino a la práctica de consumo ilimitado que lo engendra y alimenta, siendo esta tecnología la proveedora del lenguaje y el medio (en lugar de la causa o el fin último) a través de los cuales esta nueva identidad se manifiesta y reconstituye.

Conviene, pues, distinguir entre esta identidad en formación (cibernesis manifestada, por lo demás, no solo en lo simbólico sino también en lo físico, como los desarrollos de la biotecnología nos van mostrando día a día) y la adaptación o abandono gradual de hábitos anteriores de vida a este nuevo estado de las cosas, puesto que es de este desfase de donde puede surgir buena parte del cuestionamiento, negociación o matización del mismo. Pero antes de ir más lejos, quisiera detenerme en algunas de las consecuencias de la red electrónica ya no sobre la lectura, sino sobre la circulación de textos y libros. Entre éstas se encuentra la ampliación de circuitos de consumo, ventajosa para editores y autores pero riesgosa para las librerías, intermediarias en vías de reconstitución en un plano mucho más limitado, y también la liberalización, o apertura, de los canales de publicación. 
Esto último es de gran interés, pues supone una reformulación no solo del modo de circulación, sino también de los mecanismos y criterios de publicación; es decir, la decisión de qué puede y debe circular. Hasta ahora, éstos habían sido determinados por lo que podríamos llamar la dificultad de producción; o sea, el hecho de que la publicación implicaba la puesta en marcha tanto de un complejo y laborioso aparato de producción, como de un equipo (desde editores hasta impresores) que lo manejaba. Esta dificultad suplementa el importe simbólico de un texto, dotándolo de una autoridad basada en el aspecto más material de su existencia. Parte del vigor de la palabra escrita, como bien sabemos, radica en su calidad de inscripción, con preceptos literalmente grabados en piedra (tipo las tablas de los mandamientos judeo-cristianos), que establecen a la escritura, así sea en su etapa más pictográmica, como ley y legado para la posteridad.

Así, otra parte del valor de los antigüos manuscritos reside en el enorme esfuerzo que significó producirlos, labor que representa una gran cantidad de tiempo y de capital cultural, así como también unas condiciones arduas de trabajo unidas a la limitación de los materiales e incluso a su frecuente toxicidad. Esta dificultad de elaboración continúa, a otra escala, con la impresión mecánica, toda vez que la producción de libros implica una inversión de labor y materiales que rara vez llega a compensar sus costos, y menos aún a producir algún tipo de lucro (en general, las grandes casas editoriales dependen de libros de texto, revistas populares, cadenas de televisión, etc). El valor del libro, por lo tanto, reside en la combinación de su dificultad de producción con su inversión simbólica; es decir, en el modo en que reproduce aspectos del saber y de la imaginación de una cultura, así como de los valores que éstos representan.

La dificultad de elaboración juega un rol legitimante pues supone que hay un acuerdo entre un grupo específico de personas sobre la importancia de publicar, de tomarse el trabajo de producir cierto texto. Es precisamente este acuerdo el que deja de funcionar parcialmente con la red electrónica, la cual permite que cualquiera pueda poner en circulación sus escritos, otorgándoles el visto bueno del carácter impreso, aun cuando éste sea digital, sin que medie una entidad arbitrante convencional. Tal es el caso de la editorial francesa Cherche-Midi Editeur que, a modo de experimento, ha comenzado a publicar electrónicamente manuscritos de jóvenes escritores, solicitando de los cibernautas en general, en lugar de un comité editorial especializado, un consenso sobre cuáles de éstos han de conocer una publicación tradicional en papel.

La tecnología rompe así con el contrato social implícito en la publicación (así como en el diseño, la música, el cine y todo aquello que necesitara anteriormente de complejos aparatos de producción) permitiendo un acceso más democrático a la producción cultural, siempre y cuando se posean los medios y el know-how tecnológicos. Consecuentemente, pone en cuestión el proceso de legitimación, cuyos mecanismos de poder residían hasta ahora, en buena parte, en su casi exclusiva —y ciertamente excluyente- capacidad de producción material.

Nos encontramos, entonces, frente a una reconfiguración de las prácticas de producción cultural que afecta desde sus parámetros más fundamentales (quién tiene acceso a los medios de comunicación, es decir, quién tiene derecho a la palabra impresa), hasta los aspectos legales emanados de la libertad de circulación: cómo controlar, por ejemplo, la propiedad intelectual, punto de gran debate en la industria musical, o cómo obtener 
remuneración por la difusión electrónica, litigio que ha confrontado a escritores y editoriales. Con todo, el meollo del asunto es cómo establecer criterios de valor, aun cuando éstos se sepan relativos, temporales y ligados a intereses específicos. Porque a pesar de que la tecnología modifica los valores, éstos no dejan de existir; lo que ha cambiado, y drásticamente, es el peso y la repercusión del valor cultural, convertido en algo cada vez más etéreo, fugaz y arbitrario.

Quizás la mejor ilustración de este nuevo tipo de valor sea el auge comercial de las imágenes electrónicas, el cual ha producido una carrera poco difundida entre el magnate de la informática, Bill Gates, y el heredero del imperio editorial Getty. Éstos han estado comprando sistemáticamente y sin grandes alharacas desde hace varios años los bancos de imágenes impresas a fin de acaparar un mercado que hasta ahora había resultado marginal, y se mantenía básicamente del uso de imágenes en libros y otros medios tradicionales de comunicación.

El reciclaje electrónico de las imágenes nos presenta un aspecto a primera vista paradójico de la informática y de su producto principal, la realidad virtual. Habíamos visto anteriormente cómo éstas se conforman en parte a través de las características del lenguaje binario (reducción de la complejidad — material, afectiva, sensorial, factual—a través de la homogeneización y la racionalización numéricas), conformando así un nuevo modo de relación simbólica con la realidad, modo primariamente intelectual en el sentido de racionalmente cognoscitivo. Aparentemente opuestas a estas características por su variedad, figuratividad y versatilidad, las imágenes funcionan sin embargo hoy en día como su complemento, brindando el soporte visual (aunque no por eso menos simbólico) de una realidad cada vez más fragmentaria, descontextualizada e intangible.

Las imágenes tienen un impacto instantáneo debido a su condensación ("una imagen vale mil palabras”) y a su gran flexibilidad, pues incluso incorrectamente interpretadas, son siempre susceptibles de alguna lectura, de donde su valor universal. En este sentido, las imágenes son de antemano ubicuas, volátiles y aleatorias: su significado puede ser tergiversado a voluntad. A esto se añade su gradual pero sólida sustitución de la escritura como fuente primaria de representación y legitimación histórica, debido en parte al auge de tecnologías analógicas como la fotografía, la cual produce un promedio de 85 millardos de tomas por año. Así, la fotografía no ha hecho sino restablecerle a las imágenes el predominio cultural que conocieran antes del advenimiento de la prensa de Guttenberg, aunque en un contexto y una práctica completamente diferentes.

Inscritas de lleno en una economía libidinal basada en su fluidez y aparente accesibilidad (de donde su gran utilidad para la publicidad), las imágenes son la contracara placentera de la virtualidad, pantalla metamórfica donde se refleja un inconsciente que se imagina en permanente tránsito y mutuación. Controlar las imágenes, pues, es controlar ese espejo volátil pero predictivo de una identidad binaria cuya máxima originalidad estaría en la mezcla interminable de sus elementos (como sucede, de hecho, con la mayor parte de los efectos especiales, tan obvios y repetitivos), carencia creativa propia de toda inteligencia artificial. Esto, añadido a su fácil conversión y transmisión electrónicas, hace de las imágenes los elementos idóneos de una globalización tecnológica, gallinas de huevos de oro que los astutos reyes Midas han previsivamente enjaulado. 
Esta recuperación, reciclaje y revalorización virtuales de elementos ya presentes en la cultura es quizá uno de los aspectos más fascinantes de la revolución tecnológica, pues nos demuestra, como en el caso de los discos de vinil, cómo la cultura no puede ser vista como algo estático, sino como un fenómeno en continua fluctuación, algo que nace, crece, cambia, se extingue parcial o totalmente, es recuperado en fragmentos, reinterpretado, mezclado, etc, recreándose así continuamente. Esto es, la cultura es un proceso vital y no una acumulación mecánica, algo que resulta más evidente con la tecnología electrónica dada la velocidad con que estos distintos procesos se siguen los unos a los otros; solo que aquí participan de un ciclo desaforado de seducción, apropiación y descarte en el cual los elementos culturales apenas alcanzan a integrarse o desarrollarse lo suficiente como para producir algún efecto sustancial.

En otras palabras, el intercambio vertiginoso de elementos en la red electrónica provoca una transformación en la capacidad significativa de los elementos que incorpora, reduciéndolos a fuerza de fragmentación y decontextualización a sus aspectos más anecdóticos, a la vez que acrecentando infinitamente su versatilidad y consecuente rentabilidad. De este modo, tanto nuestro modo de pensar como los elementos racionales o imaginísticos que integran dicho pensamiento van conformándose paulatinamente al panorama tecnológico/comercial.

En este contexto es donde se generan los nuevos hábitos de lectura, cada vez más fracturados, dispersos e inclinados hacia lo meramente circunstancial. Aun cuando este proceso es perfectamente cónsono con la modernización de la cual es vástago, conviene entender que estas formas de lectura pasarán a ser cada vez más predominantes a medida que nuestra cotidianidad se vaya tecnologizando, haciendo de la lectura pausada — aquélla reflexiva, investigativa o meditativa - una alternativa algo obsoleta. De este modo, los libros tal y cual los conocemos pasarán a ser cada vez más marginales, valiosos tanto por su valor residual (el llevar el sello de un modo de lectura caduco pero, por lo mismo, cargado de resonancias culturales) como por su valor objetual (ser, a otro nivel, los trazos materiales de un estilo de vida en vías de desaparición).

Si bien el libro virtual, cualquiera sea su formato eventual, debería resultar mucho más ligero, aséptico y polimórfico que el voluminoso, táctil y rígido libro convencional (aparte de reducir la enorme deforestación que supone la producción de papel), cabe preguntarse si tal grado de pragmatismo vale bien el sacrificio que ocasiona a nivel de una experiencia caracterizada por la textura, la continuidad y, sobre todo, la complejidad. A mi modo de ver, lo que la tecnología pone en jaque no es solo la experiencia directa del mundo físico, sino algo que es su consecuencia immediata y en lo que las palabras, como los libros, y finalmente, sus grandes depositarias, las bibliotecas, han jugado un gran rol: la inscripción del tiempo en el espacio, los trazos de la vida, la memoria.

Es la memoria, no la cronológica, sino aquélla emocional, contingente, filosófica y poética que va quedando como una estela tras las distintas actividades humanas, lo que más se ve amenazado tanto por un pensamiento y actividad culturales altamente aleatorios, como por la indiferencia que éstos manifiestan hacia la preservación material, no numérica, de un registro social. Aquí no hay memoria artificial que valga: si ya de por sí las memorias son frágiles y precarias, susceptibles a selecciones neuróticas, fijaciones obsesivas y olvidos compulsivos, ¿cómo sobrevivirán en un sistema que las despoja de sus 
vestiduras incidentales, tales la ocasión, el implante material o la cadena de asociaciones, exponiéndolas a una desfiguración por definición anónima, un uso exógeno y temperamental, y sobre todo a la enorme vulnerabilidad de un sistema en que, a falta de agarraderos materiales, no importa cuán perecederos, y aun a despecho de una voluntad opuesta, los elementos pueden desaparecer en un abrir y cerrar de ojos sin dejar huella alguna?

Es por esto que los trazos materiales, y sus correlativos, la memoria y los sentidos, me parece representan hoy más que nunca la posibilidad de mantener cierto balance en el mundo cada vez más invisible e intangible de la tecnología. Y no porque la tecnología no dependa también de aparatos cuya obsolescencia se multiplica aún más ferozmente que aquélla de los demás objetos, sino porque a través de su sistema homogeneizador y vicarizante, la ideología tecnologística se y nos ciega a su propia inscripción material, presentándose como un circuito descentralizado cuyo poder radica en parte en su ubicuidad e invisibilidad: tal como un dios monoteico, la red electrónica está, sin ser vista, en todas partes.

Esta “desaparición” de sus elementos constituyentes, como vimos antes, y de sus operativos -desde quienes crean y organizan los espacios virtuales, pasando por aquellos que le introducen información, hasta los técnicos y trabajadores que fabrican, mantienen y perfeccionan tanto la parte “dura” como la "blanda” (la maquinaria y los programas), por no hablar de los cibernautas, seres anónimos (en tanto navegantes del espacio virtual) realza el aspecto virtual de la red electrónica. Ésta, exaltada e intensa como todo espacio imaginario, y cargada de significantes de novedad, agilidad y poder, termina estableciéndose en una autoridad todopoderosa, omnisciente, autorreferencial y regenerativa — hay quien la califica además de autística y regresiva - aun cuando a la vez se la reconozca, marginalmente, como falible, infiltrable, apropiable y finita.

Nuestra capacidad de adaptación frente a este sistema llega a sorprendernos a nosotros mismos: no hay quien, participante dosificado o adicto de la tecnología, deje de sucumbir a la fuerza centrífuga de la velocidad, impacientándose por la "lentitud" de respuesta de un mecanismo que genera en segundos lo que de otra manera nos tomaría horas o días procurar. Tal cual el binarismo que reduce el pensamiento a sus elementos más básicos, la ubicuidad y velocidad de la tecnología nos impulsan a proyectarnos como estando en todas partes a todo momento (por ejemplo, con el teléfono celular), de modo de cubrir la mayor cantidad de terreno posible con un mínimo de movimiento y de acción.

Como sugerí anteriormente, no es que el mundo de las máquinas nos vaya a desplazar. Al contrario: somos nosotros quienes gradualmente vamos a ir integrando las características de las máquinas que hemos puesto a nuestro servicio hasta convertirnos en otro tipo de ser humano. Si bien la red electrónica ha creado un nuevo tipo de comunidad cultural y facilitado nuevos modos de comunicación, es indudable que también ha contribuido a la pulverización y enajenación de un modo de intercambio social basado en la presencia y el contacto directo.

Frente a esta realidad ineludible caben algunas alternativas de resistencia o, para ser más prácticos y realistas, de adaptación crítica. A mi modo de ver, quizá la más importante es la de recordar la lección de uno de los fracasos más evidentes de la modernidad: la noción de tabula rasa. No hay tal cosa como un empezar de cero, y cualquier intento de hacerlo es su propia bomba de tiempo. Los intentos de borrar violentamente el pasado y 
las tradiciones no han hecho sino producir grandes monstruos, sean éstos una racionalidad ciega, una ciencia despiadada o un fundamentalismo desenfrenado.

Eventualmente, cada uno de nosotros tendrá que optar por su propia fórmula tecnológica, decidiendo en qué medida quiere y puede participar de esta nueva realidad. El reto es integrar y balancear el pasado con el presente, permitiéndonos así una experiencia plural y compleja de la realidad -una expansión, no reducción, de nuestra experiencia vital. 